\title{
Sobre el modernismo provinciano en México. La Casa de la Semana en Jueves de Excélsior
}

\author{
Carlos E. Flores-Rodríguez ${ }^{1}$ \\ Recibido: 21-02-2021 | Versión final: 10-06-2021
}

Resumen

\begin{abstract}
Los emergentes modos de vida de lo moderno, suscitarían discusiones en su forma de habitar. Las Ciencias Sociales, pero señaladamente las disciplinas de las Humanidades, aseguraban que todo cambio social inicia en lo doméstico, en el núcleo familiar, por lo que se preguntaban cuál y cómo sería lo adecuado para vivir lo moderno: si lo colectivo y seriado, o lo individual y aislado. Así, y patrocinada por la promesa positivista, vivienda y casa surgen, en oposición ideológica, como la respuesta a esa interrogante que se intensifica luego de la Segunda Gran Guerra. Bajo otras motivaciones, esta discusión se replicaría en ciudades latinoamericanas. Específicamente México sería referente de este debate teórico en el que la casa resultaría como la manifestación de su modernidad debido, además, a que la naciente burguesía revolucionaria adoptaría sus principios. Este sentido de clase se enfatizaría en ciudades pequeñas donde, a diferencia de las ciudades hegemónicas, no sería producto de un posicionamiento ideológico, sino de su afán aspiracional a un mundo ideal aprendido, principalmente, por el acceso a las publicaciones de época. En este trabajo, y desde una postura fenomenológica y un método historiográfico, se reflexiona sobre esta discusión y alcances. Para ello, se toma como objeto a Tepic, Nayarit; ciudad virreinal del occidente mexicano que, al igual que sus semejantes provincianas, además de carecer de estudios respectivos, las casas de esta entrante sociedad posrevolucionaria reflejarían la impostura de un modernismo de revista que anunciaba, como venta por catálogo, diseños pretendidamente universales, progresistas y científicos.
\end{abstract}

Palabras clave: Casa; publicidad; método científico; mito

Citación

Flores-Rodriguez, C. (2021). Sobre el modernismo provinciano en México. La Casa de la Semana en Jueves de Excélsior. ACE: Architecture, City and Environment, 16(47), 10371. DOI: http://dx.doi.org/10.5821/ace.16.47.10371

\section{About Provincial Modernism in Mexico. La Casa de la Semana in Jueves de Excélsior}

Abstract

\begin{abstract}
The emerging modern ways of living would provoke discussions in their lifestyles. The Social Sciences, but specifically the Humanities and its disciplines, believed every social change began in domestic spaces, at the nuclear family, so they wondered what and how would be right to live in modern times: if the collective and serial, or the individual and isolated. Thus, promoted by the positivism promise, housing and house arise, in ideological opposition, as an answer to the question that intensifies after the Second Great War. Under other motivations, this discussion would replicate in Latin-American cities. Specifically, México would be a reference to this theoretical debate of if the house would turn out to be the manifestation of its modernity due to the rising revolutionary bourgeoisie that would adopt its principles. This sense of class would be emphasized in small cities where, unlike hegemonic cities, it would not be the product of an ideological positioning, but an aspirational eagerness of an ideal learned world, mainly, by the access to period publications. This work reflects on this discussion and its scopes, from a phenomenological posture and a historiographic method. To do so, Tepic, Nayarit is taken as a case study; a viceregal city of western Mexico that, as well as its provincial analogous, besides lacking previous studies, the houses of this incoming post-revolutionary society, would reflect the imposture of magazine modernism that advertised, as a catalog sale, allegedly universal, progressive and scientific designs.
\end{abstract}

Keywords: Home; publicity; scientific method; myth

${ }^{1}$ Doctor en Periferias Sostenibilidad y Vitalidad Urbana. Conacyt-SNI-II, Universidad Autónoma de Nayarit (ORCiD: 0000-0003-0456-5378). Correo de contacto: carlos.flores@uan.edu.mx 


\section{Introducción}

Junto con la tumba y el mito, la casa ha acompañado a la humanidad en todas sus sociedades. Sea como refugio utilitario, o como manifestación simbólica; o sea como origen, o como destino, su universalidad intemporal la ha hecho, además de una categoría analítica en cualquier disciplina, un artilugio relevante para toda cultura (Gili,1999; Lévi-Strauss, 2012). Sin embargo, si hubo un tiempo en que la casa tuvo su mayor estudio, discurso y propuestas teóricas bajo la pretensión de certidumbre cientificista, fue durante el modernismo y su nuevo modo de habitar (Cox y Buchli, 2017)

México no fue la excepción. A pesar de que hay antecedentes desde finales del siglo XIX, la gran discusión sobre esta domesticidad cartesiana tendría su auge luego de la Revolución y hasta bien entrada la mitad del siglo XX. La ilusión de la promesa de in-equivocidad, infalibilidad y bienestar, tendría una mejor cabida en las ciudades provincianas a partir de su acceso a los medios impresos de alcance nacional. Una de ellas sería Jueves de Excélsior, revista cuya publicidad insertada serviría como modelo aspiracional de la clase emergente del país: la de en medio.

De eso trata este trabajo, de identificar cómo el modernismo universal se asimiló en lo local. De resaltar cuál ha sido su aporte en la identidad de lo nacional, asuntos que han sido sistemáticamente ignorados, sin reparar que la historia de las casas es la historia de sus sociedades (Jones, 2014). Para lograrlo, se toma a Tepic como objeto de análisis; ciudad media y capital de estado que, si bien no necesariamente contiene diferencias especiales a sus semejantes del país, es exactamente su ausencia de centralidad, de primacía urbana y de construcciones de autorías hegemónicas, las características indispensables para hacerla un caso relevante acorde con el sentido de la presente reflexión.

A esta relevancia debe agregársele otra valía. El método historiográfico tiene como basa el empleo de documentos adecuados para componer, progresivamente, en tiempo y espacio, el segmento de la historia que se pretende estudiar (Waisman, 1990; Bloch, 2000). En ese sentido, particularmente para esta ciudad, hay un escrito etnohistórico de carácter testimonial que describe su geografía urbana del periodo de estudio: la tesis doctoral de John Ball (1961); la cual posibilitó accederla in situ por fuentes in visu, o sea, se convirtió en una fuente singular inmejorable para construir inductivamente "uniformidades de tipo universal" (Dilthey, 1994, pág. 92).

El texto se ha dividido en cinco partes. En las dos primeras, las del fundamento teórico, se realiza un acercamiento a la modernidad como vocablo, así como algunas discusiones epistémicas del positivismo y su relación con, justamente, tal modernidad y el hábitat para, enseguida, establecer su repercusión en la construcción del México posrevolucionario y el rol de los medios impresos en el ideario y la memoria colectiva. De la tercera a la quinta, las empíricas, se plantea cómo la casa sería la depositaria de estos principios y que, a partir del sentido aspiracional de la naciente 'burguesía' posrevolucionaria, esencialmente en las ciudades no primadas, suscitarían un peculiar modernismo provinciano. En su última parte, el texto concluye respondiendo cómo se debe entender, precisamente, la casa del modernismo de la provincia mexicana.

\section{Casa y modernidad}

Aunque con cierta renuencia, Bachelard (2000) plantea la construcción del conocimiento en tres periodos. Desplegado fundamentalmente durante el siglo XIX, sería el segundo de ellos, el de "el estado científico", el que, desde su propuesta de infalibilidad y universalidad: el método; invadiría no solo los campos disciplinares, sino cualquier actividad y pensamiento humano, el cual, toda vez que

ACE, 16 (47) CC BY-ND 3.0 ES | UPC Barcelona, España | Sobre el modernismo provinciano en México. La Casa de 
es irrumpido por el evolucionismo darwinista como impulso teórico totalizador, tendería a homogenizar su lingüística (Bunge, 1980; Bochenski, 1997; García, 2006).

Este énfasis no es fortuito. Berman (1988) piensa a ese siglo XIX como el inicio de las mayores experiencias vitales que la humanidad había experimentado. Con antecedentes desde el siglo XVI, durante el XIX el cambio de vida occidental fue tan impactante que, tratando de abordar tal vorágine, no solo se le designó un vocablo (el de 'moderniste'), sino que la cuestión social dejaría de ser preocupación para convertirse, en su búsqueda por paliarla, en una problematización y objeto para su estudio, de manera tal que bajo el mencionado impulso teórico decimonónico, surgirían novedosas disciplinas con carácter de cientificidad, específicamente las de la llamada sagrada triada de las Ciencias Sociales (Wallerstein, 2007).

A estas grandes transformaciones, el propio Berman (1988) propone referirlas en dos dimensiones, ambas, advierte, desprendidas desde ese ulterior vocablo del XVIII. La una, citada bajo la noción de 'modernismo', alude al conjunto de adelantos, conocimientos y descubrimientos, "valores y visiones", así como la alteración de entornos físicos, sociales y emocionales. La otra, citada bajo la noción de 'modernidad', la ubica en un asunto ontológico, y alude a ese tumulto de experiencias vitales producto de ese modernismo.

En este juego de alcances y acepciones, el vocablo y sus variantes mostrarían polisemia. Moderno y modernismo, por ejemplo, pueden ser sinónimos (Harvey, 1998; Echeverría, 2013); mientras que modernidad tendría "tantos sentidos como pensadores o periodistas hay" (Latour, 2007, pág. 27); por lo que igual puede asociársele a lo actual, lo novedoso o transitorio, como a lo que sustituye lo caduco u obsoleto y por ello momentáneo; o igualmente para denominar a eso que es vivencial y por lo mismo vinculado a la subjetividad del individuo; o de igual forma para referirse a cualquier reciente u original reflexión teórica (Heynen, 1999).

La modernidad sería entonces la experiencia o manifestación de lo moderno o, si se prefiere, del modernismo. De esta forma, la vida moderna tendría tantas modernidades como expresiones sean posibles, pero en todas ellas, el pensamiento, método y discurso cientificista, específicamente de índole empírico analítico, serían su eje central; así que no solo temáticas como la vida cotidiana y su espacio vital -como la casa- serían incluidas, sino además cualquier actividad humana tal como la artística, la estética y, claro está, la de las ideas (McDowell, 2000; Montañez, 2009).

La aludida sagrada triada estaría embebida en su propia modernidad. A pesar del surgimiento de una filosofía antipositivista, origen de la postura epistémica fenomenológica hermenéutica, hasta mediados del siglo pasado, este campo disciplinar sería dominado por un etnocentrismo hegemónico que implicaba, entre otras cosas, un súper-positivismo y su obsesión de medirlo todo, la búsqueda de respuestas universales y por ello cerradas, así como lo hipotético deductivo como método general epistémico y de pensamiento (Mardones y Ursua, 2003; Massey, 2012).

Tales argumentos de tradición galileana se trasladarían al viejo discurso de las Humanidades. ${ }^{1}$ Así como hay un método para producir conocimiento científico sociológico, debería de haberlo tanto para la apreciación como para la creación artística. Para lo primero, surgiría a mediados del XVIII la estética que, si bien no hay acuerdo si es una rama de la filosofía o una ciencia psicológica o del idealismo, en su originario discurso se haría presente la promesa del método, su lenguaje positivista (Croce, 1982; Carritt, 1992), y "su obsesión por encontrar leyes inmutables" (Pérez, 1980, pág. 18)

\footnotetext{
${ }^{1}$ A diferencia de las Ciencias Sociales, que nacen bajo el dominio positivista decimonónico, las Humanidades como cuerpo de pensamiento se remonta a los griegos, así que hubo de adaptarse y adoptar este dominio epistemológico de forma posterior (Wallerstein, 2007; Montañez, 2009).
}

ACE, 16 (47) CC BY-ND 3.0 ES | UPC Barcelona, España | Sobre el modernismo provinciano en México. La Casa de 
Este enfoque empírico-analítico no la abandonaría. De los dieciocho métodos que Dacal (2003) propone para estudiar (o apreciar) un objeto artístico, asegura que dos serían los que recogerían con mayor insistencia esta tradición. Uno, el "positivismo lógico", impulsado por el Circulo de Viena y su racionalismo crítico, afirmaba que los juicios estéticos deberían ser de naturaleza y de verificación empírica; el otro, el "científico", haría uso de herramientas informáticas y reglas aritméticas de probabilidad y estadística para corroborar 'hipótesis' planteadas del fenómeno u objeto de análisis.

Para lo creación artística, el discurso cartesiano del método permearía también a las diversas disciplinas proyectuales (Munari, 2016). Aunque es menos sencillo dilucidar su impostura, la arquitectura como ejercicio compositivo de diseño no sería la excepción. Rossi (2015) establece que ahí el discurso científico del modernismo produciría sus propias discusiones, entre ellas su pretensión de in-equivocidad que se conocería coloquialmente como funcionalismo, por lo que funcionalismo, modernismo y ciencia, serían desde sinónimos hasta partes inseparables de un todo, pasando por su ingenuidad de extrapolar asuntos existenciales, por definición no invariables, a certidumbres universalistas de números, geometría y tipos ideales (Pérez, 1980; Ching, Jarzombek y Prakash, 2011).

A pesar de que entender lo moderno en la arquitectura pudiera ser no unívoco, eso no es del todo aplicable en su proceso de diseño, al menos en su narrativa. El método proyectual es la promesa cartesiana de infalibilidad. No importa que surjan novedosos modos de vivir lo urbano, y que produzcan un mismo número indeterminado de funciones y principios ordenadores; al final, lo cultural, lo higienista, lo estructural o de instalaciones, por mencionar algunas categorías, siempre que se piensen desde un sentido lógico-matemático de índole comtiano, serían principios de organización jerárquica-funcional igualmente válidos para un diseño presuntamente racional (Pallasmaa, 2018; Venturi, 2018).

Así que lingüísticamente, funcionalismo y racionalismo son coincidentes (Montaner, 2011). La arquitectura moderna presentaría su modernidad (su modernismo) en la racionalidad analítica del método proyectual que, junto con la función o actividad espacial, se colocaría por encima de la teoría; el método se reduce a un problema de, justamente, una organización técnica y racional que reproduce una realidad ordenada. Esta idealización forjaría en esta arquitectura su mayor mito, el ser la depositaria del triduo de la modernidad: la ciencia, la técnica y la razón (Rossi, 2018; Echeverría, 2013). Pero no serían sus únicas discusiones.

En los emergentes modos de vida de lo moderno ${ }^{2}$, una de las grandes cuestiones se centraría en lo doméstico. Tanto en el campo de la sociología (señaladamente la chicaguense), como el campo de la antropología (señaladamente la culturalista), aseguraban que todo cambio social inicia por el habitar, por lo doméstico, por el núcleo familiar. Los primeros, desde un pragmatismo funcionalista, desembocaron en asuntos de higienismo, educación y feminismo; mientras que los segundos, desde un estructuralismo, desembocaron en asuntos de emociones, significados e ideología (Ayala, 2006; Hernández, 2014).

Sin embargo, sería a partir de un tercer campo, el de las Humanidades -denotadamente desde la arquitectura como ejercicio proyectual-, en que esta cuestión tendría sus propios extremos. Las dos visiones ideológicas surgidas en el siglo XIX continuarían dominando su quehacer y reflexión: la utilitaria-pragmática y la estética-simbólica. En la primera, se primaba lo racional y lo técnico con una alta dosis ideológica y necesidades genéricas y universales; en la segunda, la del beaux art, se

\footnotetext{
${ }^{2}$ Lo moderno en el hábitat, refiere originariamente al retiro de una domesticidad que, hasta ese momento, se desarrollaba en lo público. Por lo que además de los enseres y adelantos tecnológicos, debía alojar a lo privado, entendiéndolo como una actividad especializada que ameritaba un espacio específico o exclusivo para desplegarse: las habitaciones íntimas de la casa, entre ellas el aseo personal; en ese sentido, esta práctica -y su espacio-, surgiría en el medio urbano, por lo que se asocia a su originaria clase media (Sennet, 1997; Rybczynski, 2015).
}

ACE, 16 (47) CC BY-ND 3.0 ES | UPC Barcelona, España | Sobre el modernismo provinciano en México. La Casa de 
primaba lo intuitivo y lo emocional con una alta dosis de misticismo y necesidades significantes e individuales (Colquhoun, 2005).

Estos tres campos disciplinares perderían sus límites. A principios del siglo XX, Geddes (2009) se preguntaba cuál sería el ambiente propicio para la construcción de mejores hogares: si la lógica del mercado o la del idealismo que lo niegue. Se preguntaba también qué podría satisfacer a las próximas generaciones que las habitaran: si las casas separadas o las vecindades de alturas. Aunque defendía los estudios multidisciplinares para resolver estas cuestiones sobre el hábitat individual, abogaba porque predominara la referida visión antropológica, pero, al mismo tiempo, defendía la visión cartesiana darwinista del higienismo prometido por E. Howard y su proyecto de casas individuales de Ciudad Jardín.

En cualquiera de estos extremos, y en cualquiera de estas visiones, el modernismo discurriría sobre cuál sería la respuesta adecuada. La vivienda de bloque refería a lo seriado, a las masas, a lo colectivo, a la depositaria de los adelantos tecnológicos; allí taylorismo, fordismo e higienismo se materializan auspiciados por políticas de Estado. En cambio, la casa aislada e individual, en oposición, se pensaba como el espacio de lo doméstico que mejor alojaría las nuevas formas de habitar lo moderno. En ambas hay despliegue de la vida cotidiana, solo que la vivienda, desde categorías positivistas en su diseño, y la deducción y las teorías generalistas como método, tendería a satisfacer el Modo de Vida, mientras que la casa, desde herramientas etnográficas-fenomenológicas en su diseño, la inducción y las propuestas individuales como método, tendería a hacerlo con el Estilo de Vida (Montaner y Muxí, 2013; Hernández, 2014; Puente, 2016).

Al final, sería en la casa donde ambas visiones aparentemente excluyentes no estarían en desacuerdo. El sueño lecorbusiano de vivir eficientemente conviviría con el bachelardiano de habitar poéticamente. Ahí, si bien se conservarían los atributos utilitarios o pragmáticos, estos se supeditarían a los culturales, por lo que la casa individual se constituiría en "el modelo para alcanzar el deseo y las intervenciones particulares" (Liernur, 2007, pág. 13), en aquella imagen aspiracional al que todo nivel social se adecuaba (Vapñarsky, 1963), en el lugar propicio para sentirse seguros y protegidos, y en donde se gestaría una pretendida universalidad-homogeneidad, es decir, la reproducción de una realidad idealizada, en otras palabras, en la manifestación -o la modernidad- de lo moderno.

\section{México y posrevolución}

Después del conflicto armado interno, el país se volcaría en la búsqueda de estabilidad y de identidad. Sentimientos de pertenencia y nacionalismo se hicieron presentes en el arte y la arquitectura; distintivamente en esta última actividad, la gran riqueza de escritos y medios impresos jugarían un papel preponderante para su difusión y análisis, gestándose una alta tradición literaria sobre su pensamiento y discusión ${ }^{3}$, de manera tal que durante el siguiente medio siglo, México se convertiría

\footnotetext{
${ }^{3}$ Como acercamiento a esta literatura, se sugiere el prólogo del volumen IV de Vargas y Arias (2010), donde se hace referencia a estos impresos y su ideología de momento. El mismo Vargas (2009, pág. 14) presenta en tres tomos a "esta gran riqueza cultural sobre los idearios de los constructores de buena parte del México que hoy conocemos". Por su parte, Enrique de Anda y Salvador Lizárraga realizan en el 2010 una extensa compilación de textos sobre la modernidad y su pensamiento. Hay además una tesis doctoral, que fue llevado a libro, de Fernanda Canales que en el capítulo 3 "arquitectura impresa" revisa "cerca de 450 libros realizados en el siglo XX sobre la arquitectura en México, incluyendo desde gruesos volúmenes hasta pequeños panfletos" (Canales, 2013, pág. 217). En el universo de las revistas, Gutiérrez y Méndez (2009) destacan el caso mexicano de Latinoamérica por su volumen, continuidad y diversidad. Es Louise Noelle (2009) quien hace la revisión de cada una de ellas concluyendo que, precisamente por su riqueza, son un pilar de reflexión de la arquitectura del siglo XX. De todas ellas, Leidenberger (2012) asegura que tres serían las más protagónicas en esta discusión teórica de la arquitectura posrevolucionaria mexicana, siendo La Sección de Arquitectura, publicada por el diario Excélsior, una de ellas.
}

ACE, 16 (4.7) CC BY-ND 3.0 ES | UPC Barcelona, España | Sobre el modernismo provinciano en México. La Casa de

la Semana en Jueves de Excélsior. DOI: http://dx.doi.org/10.5821/ace.16.47.10371 
en el referente latinoamericano y "vigoroso centro de debates teóricos" de la arquitectura y el modernismo (Segawa, 2010, pág. 12).

Si toda arquitectura nace de las ideas, son mayormente reproducibles una vez que se plasman (Rueda, 2016). Su reflexión se dividiría entonces entre quienes las escriben y entre quienes las leen o interpretan (Anda, 2010). Sin embargo, en el caso mexicano, a pesar de que la gran mayoría estarían dirigidos a un público ilustrado, no debe olvidarse que la visualidad se pondría por encima de la oralidad; a saber, las ilustraciones de la pujante fotografía, hacía que en el contenido de dicha literatura predominara una gran riqueza gráfica en detrimento de las discusiones teóricas y a favor, como principio aristotélico, de quienes la consumían (Ortiz,1998; Dorotinsky, 2014; Ong, 2016).

Al respecto, la publicidad insertada en estos medios impresos tendría dos cambios significativos. Uno, que los ideales europeos de antes de la Revolución, migrarían al ideal de la cultura estadunidense; y dos, que mucha de esta publicidad estaría insuflada con la tendencia de consumo del hágalo usted mismo, muy de auge en las décadas del 30 y del 40 del siglo XX (González, 2015). Lo que no cambió fue el objeto y el destinatario de tal publicidad; o sea, seguía buscando homogeneizar, seguía buscando unificar el ámbito de lo público con lo privado, y seguía dirigiéndose al consumo de la burguesía; pero para esta nueva etapa, sería a la naciente burguesía posrevolucionaria, esto es, la clase media urbana (Cuevas, 2010; Habermas, 2016).

En esta afirmación, uno de los medios escritos más divulgados, y que especialmente influiría en las ciudades de provincia mexicana, serían los diarios y sus suplementos. Particularmente a Excélsior se le reconoce en esta época una gran tradición en temas sobre arquitectura, notoriamente, en su denominada La Sección de Arquitectura (Leidenberger, 2012; Canales, 2013). Empero, dos de sus semanarios abordarían también esta temática: Revista de Revistas y Jueves de Excélsior. La primera, en su eclecticismo, eventualmente tendría artículos y publicidad sobre esta materia. La segunda, no obstante, sería la que mostraría un papel destacado, pero no en la reflexión, sino en propuestas de arquitectura doméstica en la que las ilustraciones tendrían protagonismo.

Jueves de Excélsior aparece en 1922 como uno de los suplementos del diario Excélsior. Hasta su último número en 1994, colocaría en su tiraje semanal temas políticos y de la cultura nacional con un diseño enriquecido con ilustraciones, donde el lenguaje e ímpetu de certidumbre llegaría también a sus anuncios publicitarios marcando época en el ideario y la memoria colectiva. A partir del número 1627 (de septiembre de 1953), hasta el número 3373 (de marzo de 1987), usualmente en el reverso de la contraportada mostraba impreso un plano arquitectónico identificado con un número de proyecto de autor para su venta. En sus más de tres décadas de vida, publicaría cerca de mil seiscientos prototipos de casas ${ }^{4}$.

Con el título de La Casa de la Semana, en la práctica, este conjunto de planos se reuniría en catálogos que, de vez en vez, se comercializaban en compilaciones. Su éxito comercial radicaba en la facilidad de su acceso y lectura, en su alcance geográfico, y por el prestigio del diario que los promovía. Así que lejos de ser un medio de reflexión y discusión, sería de persuasión publicitaria de un reducido número de autores ${ }^{5}$, por lo que el proselitismo de su lenguaje obedecía más a los intereses e ideología de estos profesionales del diseño (convertidos en vendedores por correspondencia) quienes, a la vuelta de correo, y previo pago, hacían llegar "[...] los planos constructivos [...] dibujados a escala, con

\footnotetext{
${ }^{4}$ En muchas ocasiones, aunque con número de proyecto diferente, las propuestas se repetían en diferentes números de revistas. Aún con el nombre de La Casa de la Semana, se presentaban géneros de edificios variopintos, tal como estaciones de gasolina, rastros, salas de cine, templos religiosos, granjas, cafeterías, salón de eventos y hospitales, entre otros

${ }^{5}$ Una primera etapa los proyectos estarían firmados por el Ing. Darío Argüelles y, ocasionalmente, por el arquitecto Luis G. Rivadeneyra Falcó; mientras que, en una segunda, alternarían eventualmente con el arquitecto William A. Schermer y con el arquitecto Rogelio Campos Guzmán, quien dominaría hasta el último número.
}

ACE, 16 (4.7) CC BY-ND 3.0 ES | UPC Barcelona, España | Sobre el modernismo provinciano en México. La Casa de 
todos los detalles arquitectónicos, sanitarios y estructurales [...] por juegos de cinco copias" (prototipo ำ 23-XII-156).

Divulgada como "página especial" o como "nueva sección", estos productos de consumo colectivo se publicitaban con un alcance nacional. En sus textos de referencia, además de utilizar casa o vivienda como epíteto intercambiable, longitudinalmente posibilita realizar dos tipos de lecturas. Por un lado, muestra la evolución del lenguaje y la representación gráfica, así como las etapas estilísticas (mismas que van desde un funcionalismo decorativo hasta el angulado y acristalado internacionalismo); por otro, el discursivo, va desde un sentido altruista y de servicio social, hasta la divulgación idealizada de la cientificidad y racionalidad de los proyectos ofrecidos.

Por ejemplo, el año de salida, en el prototipo ㄲo 1 de septiembre, anuncia que:

El Jueves de Excélsior, a través de esta página que aparecerá semanalmente, difundirá la vivienda racional, práctica y económica, ofreciendo a nuestros lectores un servicio completo de planos constructivos detallados y preparados para la inmediata ejecución de la obra.

Un mes después, en el prototipo o 3 y no 5, informaba que:

El Jueves de Excélsior intentando cubrir en parte una necesidad de orientación técnica, en lo que a la construcción de la vivienda se refiere, necesidad tanto mayor para aquellos pueblos de nuestra República que carecen de ayuda profesionista es por lo que, con miras al cumplimiento de una función social, dedicamos esta página a la construcción técnica de la vivienda.

Jueves de Excélsior, con miras a divulgar ideas de viviendas prácticas y científicamente planeadas, ha iniciado la publicación de esta página espacial titulada 'la casa de la semana' en donde nuestros lectores encontrarán modelos de casas y casitas de diferentes tipos y costos.

Ya en noviembre del mismo año, en el prototipo no 10, reitera su altruismo, cientificidad e intencionalidad financiera:

Jueves de Excélsior cumpliendo su función social difunde a través de esta página ideas y problemas ya resueltos de la vivienda racional y científicamente planeada. Es nuestro primordial objetivo el cubrir una necesidad que se deja sentir en algunos pueblos de nuestra República en donde no existe el técnico en la materia. Hemos editado en láminas de papel heliográfico el primer álbum, de los proyectos constructivos del Jueves a \$15.o cada ejemplar.

Igualmente, y debido a la publicitada facilidad y practicidad de los planos, animaba al referido Hágalo usted mismo, así como a la autopromoción. En octubre del año siguiente, en el proyecto no 44, establecía:

Proyecto de Jueves de Excélsior, invita a los lectores que hayan ejecutado los proyectos que se publican en esta página a enviar las fotografías de la obra ya realizada para ser expuestas en esta sección. Indíquenos el lugar, nombre del ejecutor y costo alcanzado.

Y en el proyecto no 52-A, repetía sus bondades:

Los planos constructivos de todos nuestros modelos son detallados y calculados, toda persona que posea un mínimo de conocimientos sobre esta materia puede, con ayuda de nuestros planos, dirigir y construir obras de este tipo, pues indicamos paso a paso todo el proceso de la obra.

Fundamentalmente en sus primeros años, la inserción de anuncios publicitarios en esta página se haría presente. Desde aquellos que los vincule con organismos de reciente creación; como el prototipo no 60 donde aclara que la página se realiza "[...] con el fin de cooperar con el Instituto Nacional de Vivienda [...] creado recientemente", hasta la promoción de algún producto de decoración o material de construcción; como el prototipo no 64-B que denominaron 'Casa Delher' en alusión a productos de una marca que, se asegura, son “[...] los más antiguos y experimentados fabricantes de equipos de cocina [...]". Por su parte, las leyendas de cientificidad, altruismo y de autodirección,

ACE, 16 (4.7) CC BY-ND 3.0 ES | UPC Barcelona, España | Sobre el modernismo provinciano en México. La Casa de 
dilatarían un poco más en desaparecer, no así la autopromoción del propio proyecto y de su autoría, que permanecerían hasta su último número.

\section{Casa y modernismo en México}

La primera mitad del siglo XX. México vivía un frenesí urbano y arquitectónico. Así que además de ser referente de debates y de ideas, para Ricalde (2007) no es exagerado pensar que el modernismo latinoamericano tendría aquí su epicentro. Rivera (1996) propone su instalación en dos tiempos. El primero sucede en las entreguerras. Superado el eclecticismo, se produciría un funcionalismo sin teoría, "espontáneo", ingenuo e intuitivo fruto del "talento personal" de quienes tuvieron contacto con esta arquitectura y con publicaciones, escritos y slogans denotadamente de Le Corbusier. Esta etapa de búsqueda vanguardista, Jiménez (2007, pág. 126) la propone como la del "Renacimiento Mexicano".

El siguiente, luego de la Segunda Gran Guerra, se desarrolla dentro de un par de posiciones. En la primera estarían quienes colocarían a la 'función' en un plano cuasi mágico. Omitirla en el diseño de lo doméstico, es condenar a la sociedad a la promiscuidad o la desintegración familiar y la pérdida de valores familiares (Ramírez, 1963). El método, diagramas, tablas, formulas y cálculos entronan al programa como basa de este funcionalismo dogmático que, como delirio, se consolida en el lenguaje del diseño con la llegada a México de quien es considerado el director más radical de la Bauhaus: Hannes Meyer y su propuesta de arquitectura científica. Toda actividad puede ser traducida a un algoritmo: el algoritmo del hábitat ${ }^{6}$ (Lazo, 2007). El programa, desde el discurso científico, se convierte así en una construcción de una realidad que, incluso, llega a sustituirla

(Heredia, 2007).

En la segunda se establecían dos posturas. Una, la progresista, se definía desde un funcionalismo internacionalista; de una arquitectura "de mínimos que se creyó científica [y de] credo político" (Canales y Hernández, 2017, pág. 18). La otra, la nacionalista, se definía como un "racionalismo a la mexicana" de la que paradójicamente al polaco Mathias Goeritz se le reconocería como su inspirador a partir de un texto de su autoría denominado Manifiesto de Arquitectura Emocional (Ricalde, 2007). De fuerte dadaísmo, ahí afirma que la arquitectura es una incompletud emocional solo acabada con la imaginación del espectador-habitante; los espacios, como la poesía, deben ser moldeados a voluntad, desde un constructivismo (Goeritz,1960). Más allá de todo ello, Jiménez (2007) asegura que en México la arquitectura moderna nace por las casas. Esencialmente dos casas de dos autores -una en cada postura-, serían las edificaciones que mejor representen este modernismo mexicano: la casa estudio de Luis Barragán ${ }^{7}$ y la casa de Juan O 'Gorman para los pintores Frida Kahlo y Diego Rivera ${ }^{8}$ (Figura 1). ímpetu

\footnotetext{
${ }^{6}$ Nada nuevo. Desde principios del siglo pasado se advierte el uso de diagramas de micro movimientos en el diseño de casas para 'eficientar' desplazamientos espaciales. Este "mínimo esfuerzo" fue propuesto por Lilian Gilbreth, aunque estaba destinado para hábitos personalizados, particularmente de la cocina, la herramienta se universalizó (Rybczynski, 2015; Canales 2021).

${ }^{7}$ Luego de un encuentro personal con Le Corbusier, la casa no sería solo una máquina para vivir, sino "para que el espíritu se desarrolle y viva agradablemente” (Ramírez, 2017, pág. 26); con ese impulso, Barragán construye en Guadalajara la casa del muralista Clemente Orozco, donde, a juzgar por Díaz (1991), los muros y los espacios cerrados se reivindican y se procuran (Figura 1).

${ }^{8}$ Con un notable paralelismo plástico con el estudio taller que Le Corbusier construye en 1922 (en Paris) para el pintor Amédeé Ozefant (Jiménez, 2007), de esta casa se duda sobre si fue la primera obra moderna en México. El año de su manufactura coincide con el de la casa Gómez Morín de Carlos Obregón Santacilia, ambas, con otra gran similitud, su discurso plástico disruptivo con una enorme influencia lecorbusiana manifestada por muros en ángulos, ventanas continuas, asimetría y ausencia de ornamentos. Pero a decir del propio O 'Gorman, "la primera casa funcional en México" sería en realidad la construida por él mismo para sus padres en 1928 (Anda, 2007, pág. 156) (Figura 1) que, en realidad, es una copia de un prototipo de un bloque vivienda "del edificio de narkomfin en Moscú de Moisej I. Ginzburg e I. F. Milinis (1928-1930)" (Olivares, 2011, pág. 4). Sin embargo, dice López (2015) que debido a la proclividad de O'Gorman para manipular fechas y firmas de sus obras, este merito, por el año de manufactura, es de las Casas Gemelas de los arquitectos Paul Artaria y Hans Schmidt construidas en 1929 en la colonia del Valle de la ciudad de México. Aunque
} 


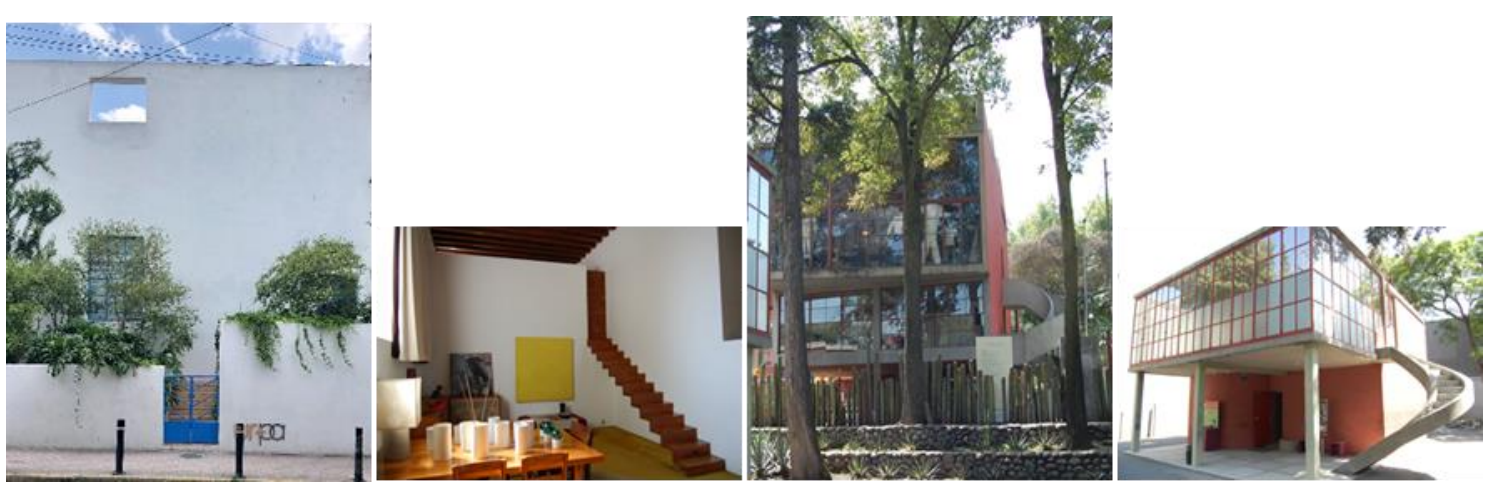

De izquierda a derecha. Fuente Casa Orozco: Fotografía del autor. Fuente Casa Estudio de L. Barragán, Casa Estudio de Diego Rivera y Casa para los padres de J. O 'Gormán: Fotografía de Raymundo Ramos.

Por su parte, Mayne (2019) considera que la arquitectura del siglo XX está destinada a ser la más influyente en el actual y futuro diseño de la arquitectura del planeta. De las 100 edificaciones del mundo que propone The Now Institute como referenciales, por su discurso arquitectónico y significantes, veintiuna son casas. Para México plantea tan solo una edificación con estas características, y es una casa, la mencionada casa estudio Barragán, a quien lo refiere como un moderno "no europeo" (Figura 1). A tal arquitectura emocional, al mismo tiempo que la define como banal y coreográfica, la coloca como una experiencia y un oasis (Mayne \& Now Institute, 2019). Este símil bien puede servir como conjetura genealógica de la casa del modernismo mexicano: no es lineal, pero sí contradictoriamente polivalente.

\section{Casa y modernismo en Tepic}

Más allá de dilucidar si ha sido la casa de O 'Gorman, o la de Santacilia, o la de Artaria y Schmidh la primera obra moderna en México, la casa de las ciudades sería donde los principios del modernismo se cebarían (Núñez, 2002). Ahí también se extendería esa aspiración que toda sociedad posee de manera natural a lo que considera mejor o superior, y la casa de la clase privilegiada sería uno de los objetos de inspiración para materializarla (Vapñarsqui, 1963). Si ambas premisas son ciertas, debe matizarse con un par de cuestiones que, por otro lado, no se entienden separadas. La primera es que esta imitación no sería de cualquier casa, y la segunda es que lo moderno se manifestaría, también como signo de modernidad, en un súbito y acelerado crecimiento urbano y sus consecuentes ordenanzas de control.

En la primera cuestión, esta aspiración de clase se movería en tres sentidos. Uno, se carecería de los medios y la cultura para contratar un profesional de diseño o para vivir en las zonas de mayor plusvalía; dos, la exigencia en la mayoría de las ciudades de presentar un plano arquitectónico previo a su construcción ${ }^{9}$ y; tres, hay un afán de no parecerse a las clases consideradas inferiores, por lo que vivir en la periferia de la ciudad, específicamente en una colonia ${ }^{10}$, y construir sin un plano, no es

Hannes Meyer aclara que, al ser hechas por dos arquitectos suizos, para dos familias suizas, y para costumbres suizas son, en realidad, casas modernas suizas hechas en el extranjero (Meyer, 1941). Esta discusión, bien puede continuarse con el texto de Heredia (2020).

${ }^{9}$ En ciudades como Tepic, la obligatoriedad de un plano constructivo aparece en 1940, según Decreto 2022 de mayo de 1940, reafirmándose en febrero de 1946, según Decreto 2765.

${ }^{10}$ En oposición a fraccionamiento, o colonia residencial, la colonia se asociaba a pobreza, a lo popular y lo marginal; en general a la ausencia de planeación y de servicios urbanos, los cuales quedaban bajo la discrecionalidad y responsabilidad pública, usualmente municipal.

ACE, 16 (47) CC BY-ND 3.0 ES | UPC Barcelona, España | Sobre el modernismo provinciano en México. La Casa de 
opción. Así que sus casas, al buscar las condiciones de las superiores y distanciándose de las inferiores, las coloca en medio. Esta libertad para adaptarse a los extremos, si Rybczynski (2015) tiene razón, sería lo que a la postre reflejaría más genuinamente el sentido de lo moderno.

La descrita situación se acentuaría en las ciudades pequeñas, particularmente las consideradas provincianas. Ahí, con mayor ahínco, la modernidad de sus casas no serían producto de un posicionamiento ideológico o de una reflexión teórica estilística. Es más bien un resultado de ese afán por parecerse -o alejarse- de un ideal: la emulación -o el rechazo- de un estilo de vida reflejado primordialmente en el diseño de su fachada y la secuencia, características y número de sus espacios domésticos; por lo que obedecería a la ilusión de un mundo idílico, de un futuro inventado, de un modelo de imitación igualmente idealizado, de una búsqueda aspiracional que, solo por ello, atraería variadas situaciones, muchas de ellas contradictorias.

En ese aspecto, se reconocen como cinco las fuentes que mayor contribuirían al ingreso y dilatación de la modernidad en la casa tepiqueña (Flores, 2019). Si bien todas forjarían una interpretación local, el contacto con esta estilística sería la que mayormente participaría en la construcción de la casa de este modernismo provinciano. Hay referencias de un contacto directo, auspiciado por los viajes de los propietarios o constructores a otras ciudades, pero sería el indirecto, específicamente por la facilidad de acceso a las publicaciones de época, el mayor promotor de la construcción de las casas de esta clase media, marcadamente por la repetición aprehendida del dueño, del maestro de obra o del dibujante quienes “copiaban o imitaban estampas o ilustraciones” (Gómez, 2016, pág. 31).

En la segunda cuestión, la del crecimiento de una ciudad, Pöete (2015) asegura que éste está determinado, principalmente, por el desarrollo y advenimiento de sus viarios y redes de comunicación comercial. Pese a que la llegada del FFCC produjo cambios importantes en muchas ciudades mexicanas, para el caso de Tepic, su factor de modernidad sería posterior a la Segunda Guerra Mundial y se debe, particularmente, a la introducción a principios de la década del cincuenta, de la carretera México-Nogales y de las rutas aéreas a las ciudades de México y Tijuana, eventos que modificarían severamente su estructura y funcionamiento (Ball,1961).

De lo anterior, urbanísticamente tres consecuencias pueden establecerse. Un flujo comercial dentro y fuera de la región y del país; una gran migración local y extranjera: en la siguiente década la población tepiqueña se duplicó y; el crecimiento de la ciudad más allá de sus históricos límites virreinales: en esa misma década dieciséis nuevas colonias serían fundadas. De manera tal que, en los siguientes quince años, luego de la referida gran guerra, Tepic tuvo más cambios y crecimiento que en sus anteriores cuatro siglos de vida: una ciudad moderna emerge dejando de ser esa ciudad apacible, tranquila y provinciana (Meyer, 1997).

Ball (1961) asegura que para esta emergencia urbana Tepic carecía de leyes urbanísticas. Esto no es del todo cierto. Desde la segunda mitad de la década del treinta, entre otras ordenanzas, la ciudad disponía de instrumentos de planeamiento urbano en los que la 'zonificación', contenida en un 'plan patrón', estaría presente (Decreto 1781); de una Ley que normaba las promociones urbanas del extrarradio, denominadas colonias (Decreto 1797); y de la obligatoriedad de un plano arquitectónico como requisito para construir cualquier edificación (Decreto 2022), entre ellos la casa. Esta última ordenanza, aparte de motivar el oficio del dibujante, al centrarse más en elementos de seguridad estructural y de higienismo, permitiría que asuntos como la estilística, o propiamente de diseño, quedara bajo la discrecionalidad del habitante y de la habilidad de quien dibujaba (Figura 2), por lo que, como se ha dicho, 'calcar' proyectos o planos de medios impresos se convirtió en un hábito (Rueda, 2016).

ACE, 16 (47) CC BY-ND 3.0 ES | UPC Barcelona, España | Sobre el modernismo provinciano en México. La Casa de 
Figura 2. Plano para obtener Licencia de Construcción y Anuncio publicitario de dibujante de planos

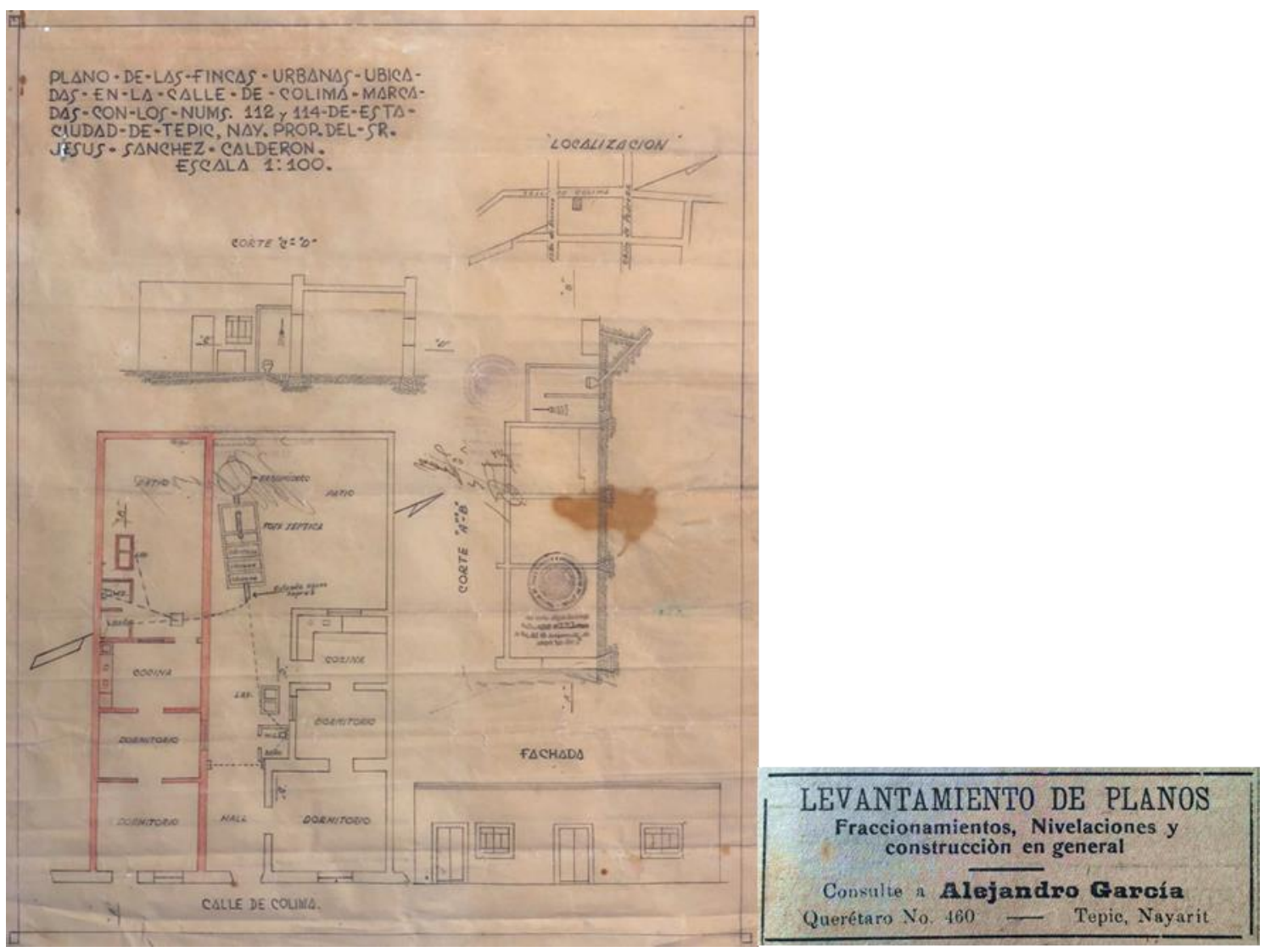

Fuente del Plano: Colección personal. Notas: El plano es de 1950 y es para dos casas contiguas de la colonia San Antonio; ahí se observan espacios como la suite continua, la cocina de hornilla de leña y el baño exterior de letrina. Fuente del anuncio: Periódico El Heraldo de Nayarit, Semanario Independiente; Tepic Nay., 12 de noviembre de 1932; Hemeroteca Digital de Nayarit.

Además de los citados viarios y redes, el emergente desarrollo de la economía de Tepic se vería reflejado en su crecimiento urbano (Ball, 1961). En ese sentido, como se ha planteado, su mayor expansión sería entre 1945 y 1960; durante ese lapso se fundaría poco más de una colonia11 al año, sin embargo, y de acuerdo con el nivel social y económico, cuatro promociones urbanas serían las mayormente depositarias de las casas del modernismo tepiqueño de su primera etapa: Residencial La Loma, Estadio, San Juan y Versalles. A excepción de la primera, encaminada a una pretendida clase alta, las últimas tres estarían dirigidas a esta entrante clase media posrevolucionaria.

De 1946, la Estadio se anuncia como la primera promoción "exclusiva". Se distinguiría de sus contemporáneas por deslindarse del calificativo de "colonia" y autonombrarse como "un verdadero Fraccionamiento”. Por su parte la San Juan, de 1954, al igual que la anterior, sería catalogada como "suburbana". La Versalles, de 1958, y colindante a la anterior, sería publicitada como "elegante" y "exclusivamente residencial". Todas ellas con pretensiones de clase, estaban dirigidas a imaginarias personalidades del mundo social tepiqueño (Flores, 2015). De cada diez casas de este periodo, al menos dos serían construidas por este estrato medio, quienes no dudarían en imitar el idílico modelo

\footnotetext{
${ }^{11}$ Como la referida colonia San Antonio, de 1944 que, por su fecha de aparición, se constituye como la primera promoción urbana posrevolucionaria de Tepic.
}

ACE, 16 (47) CC BY-ND 3.0 ES | UPC Barcelona, España | Sobre el modernismo provinciano en México. La Casa de 
ofrecido por Jueves de Excélsior, en donde adaptación, o franca copia de los proyectos, serían los modos más socorridos en esta búsqueda aspiracional de clase.

Para el primer modo, dos casas son notables. El proyecto no 2, denominado "Veracruz", es uno de ellos. Aparecido por primera vez en la revista número 1630, se trata de la casa construida en el número 33 de la calle Circuito Estadios del Fraccionamiento Estadio. De funcionalismo decorativo, es un proyecto de una planta con jardín exterior y porche, como espacios de transición; cocina, comedor y estancia, como área pública, estando estos últimos en una suite corrida; y dos habitaciones y baño americano interior, comunicados con un pasillo, como área privada. A manera de detalle, se observa una chimenea aparente con elementos decorativos del art déco (Figura 3).

Figura 3. Proyecto № 2 de Jueves de Excélsior y Casa № 33 del Circuito Estadios del Fracc. Estadio
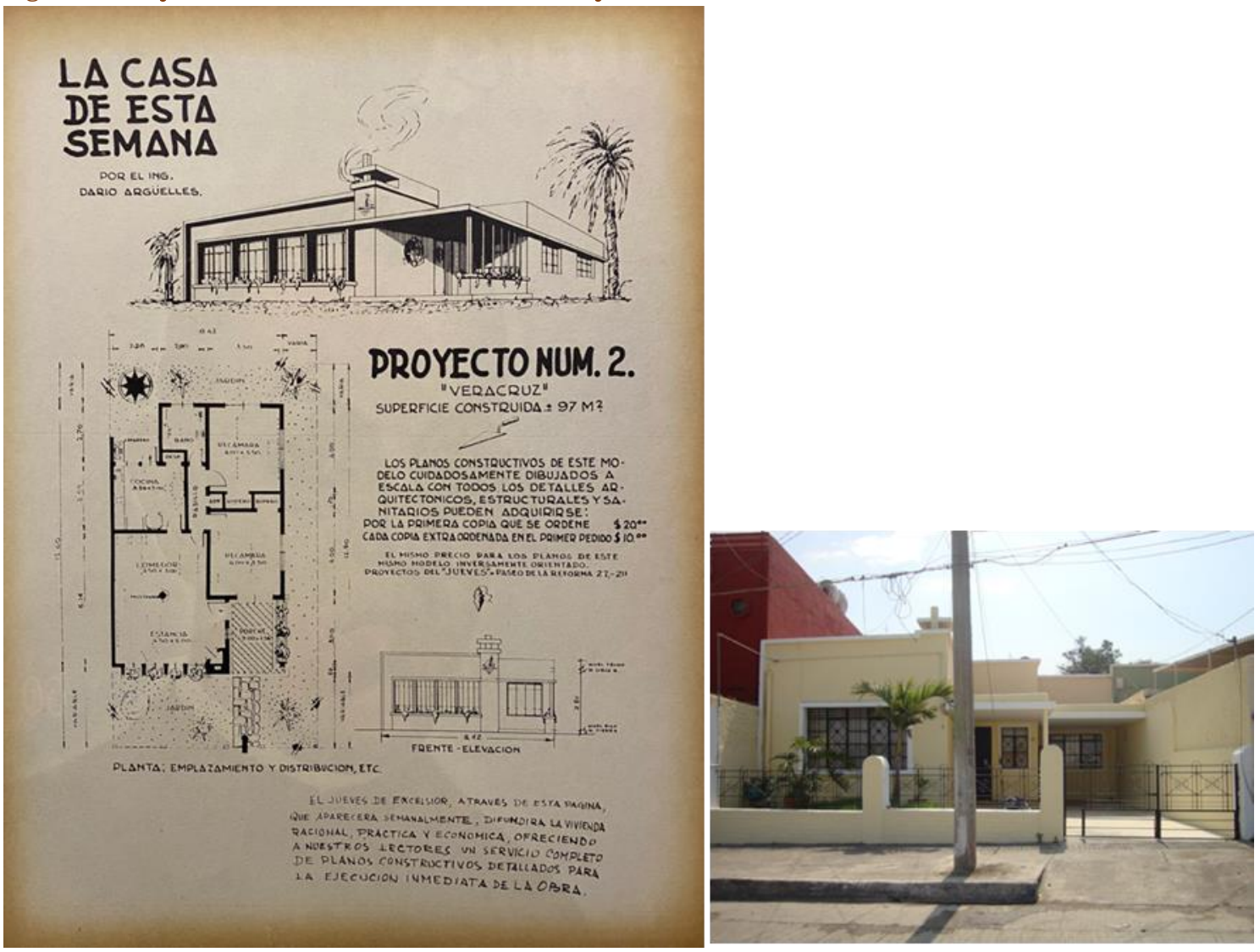

Fuente del proyecto: Revista Jueves de Excélsior no 1630 del 8 de octubre de 1953; Hemeroteca Histórica de la Biblioteca Pública del estado de Jalisco: Juan José Arreola. Fuente de la imagen: Fotografía del autor.

La otra casa se daría en el fraccionamiento Versalles. Localizada en el número 296 de la calle Acacia, la casa estaría basada en el proyecto número 89 aparecido por vez primera bajo el nombre de "Morelos" en la revista no 1757 del 22 de marzo de 1956. De un funcionalismo racional, ésta se compone de dos niveles con jardín exterior y porche, como espacios de transición; cocina, comedor y estancia, como área de servicio y pública, todos ellos espacios vinculados pero independientes; tres habitaciones con un baño americano interior compartido, como área privada. La planta alta es una gran terraza descubierta que comunica un estudio y una habitación con baño americano en común. A manera de detalle, se observa una chimenea funcional (Figura 4). 
Figura 4. Proyecto № 89 de Jueves de Excélsior y Casa no 296 de la calle Acacia en el Fracc. Versalles
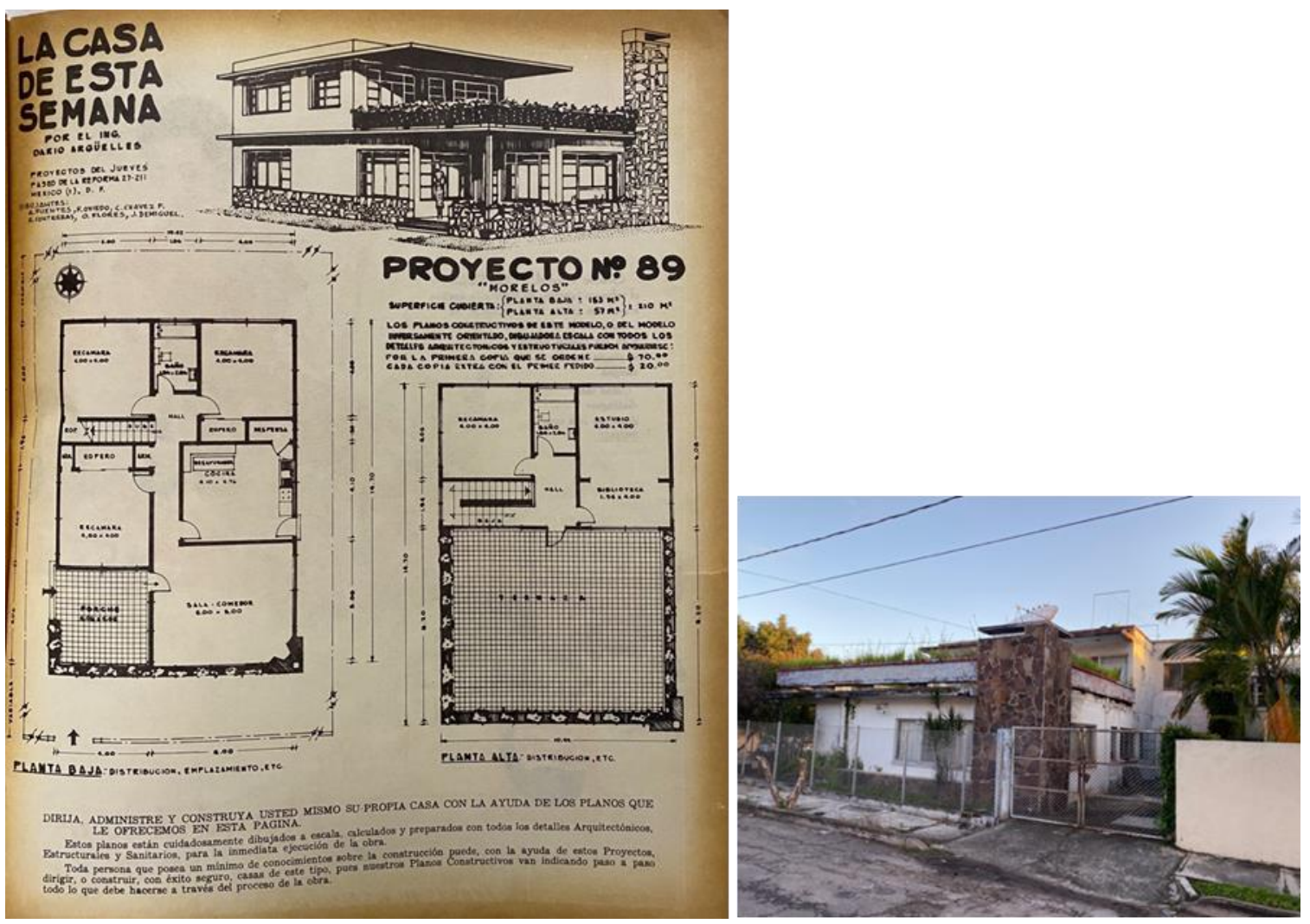

Fuente del proyecto: Revista Jueves de Excélsior no 1757 del 22 de marzo de 1956; Hemeroteca Histórica de la Biblioteca Pública del estado de Jalisco: Juan José Arreola. Fuente de la imagen: Fotografía del autor.

El segundo modo, el de la copia, dos casas serían también las representativas. La primera en la colonia Versalles, se trata de una casa ubicada en el número 11 de la calle Country Club en donde es visible la calca de un proyecto aparecido por tercera ocasión con el nombre de "La Gloria" en el no 81 de la revista número 1741 del 1 de diciembre de 1955. Con características estilísticas del spanish revival, se trata de una casa de una sola planta que se eleva artificialmente respecto a la calle. Consta de porche, vestíbulo, estancia y solárium en semicírculo, comedor, cocina, costurero, tres habitaciones y un baño interior común tipo americano. Todos los espacios tienen puerta de ingreso que los hace independientes entre sí. Se manifiesta como detalle, de nueva cuenta, una chimenea funcional (Figura 5).

La segunda casa de calca se encuentra en el número 101 de la calle Paraíso en la colonia San Juan. Repetida en variadas ocasiones, aparece por última vez en la revista número 1778 del 16 de agosto de 1956 con el nombre de "Aridem" y con no de proyecto 99-E. De funcionalismo decorativo, es un proyecto de una planta con jardín exterior circundante y porche; comedor y estancia con chimenea, como área pública en una suite corrida; cocina y dos habitaciones con baño tipo americano interior, comunicados con un pasillo, como área privada (Figura 6). 


\section{ACE Architecture, City and Environment}

Figura 5. Proyecto № 81 de Jueves de Excélsior y Casa № 11 de la calle Country Club Fracc. Versalles
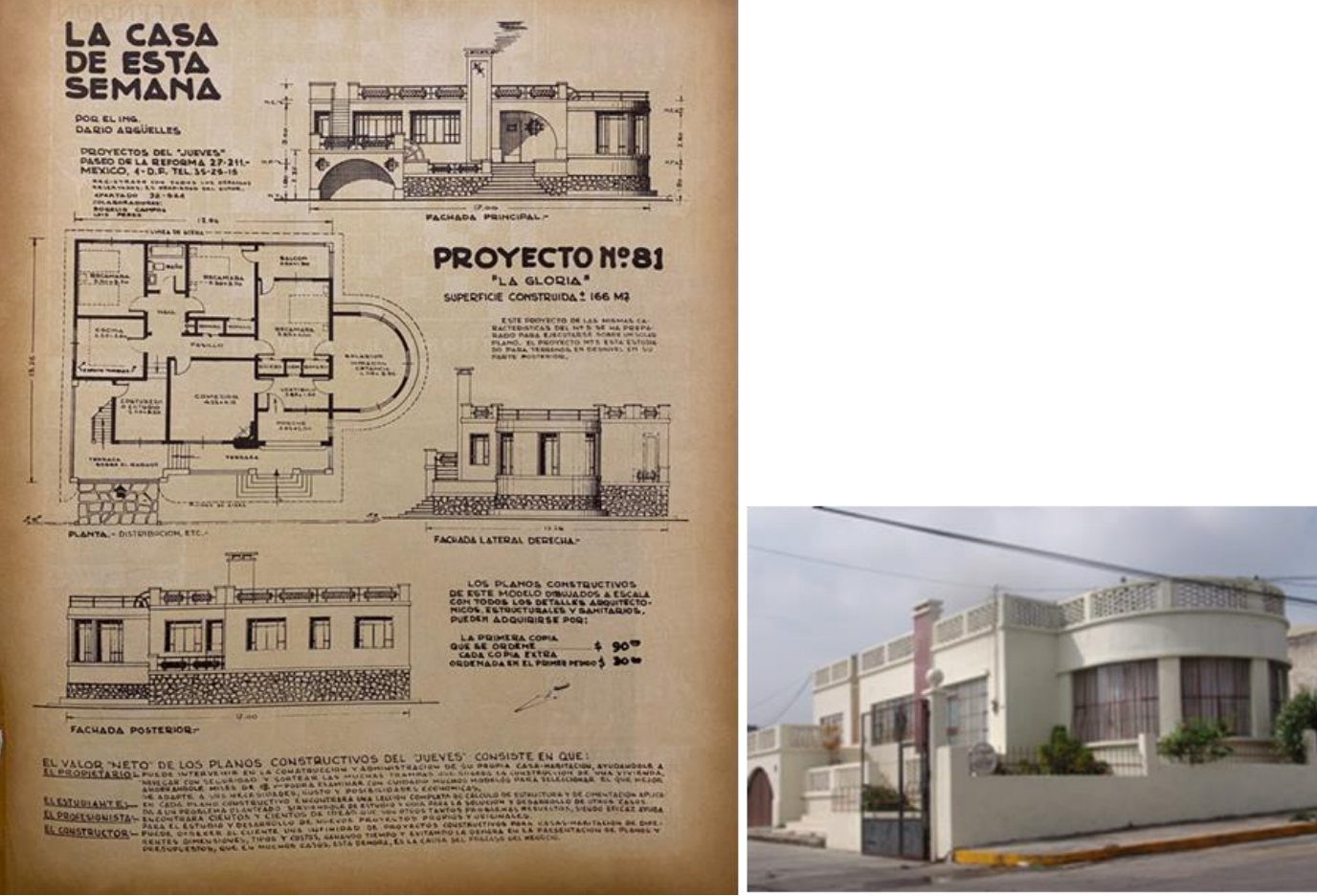

Fuente del proyecto: Revista Jueves de Excélsior no 1741 del 1 de diciembre de 1955; Hemeroteca Histórica de la Biblioteca Pública del estado de Jalisco: Juan José Arreola. Fuente de la imagen: Fotografía del autor.

Figura 6. Proyecto no 99-E de Jueves de Excélsior y Casa no 101 de la calle Paraíso de la col. San Juan
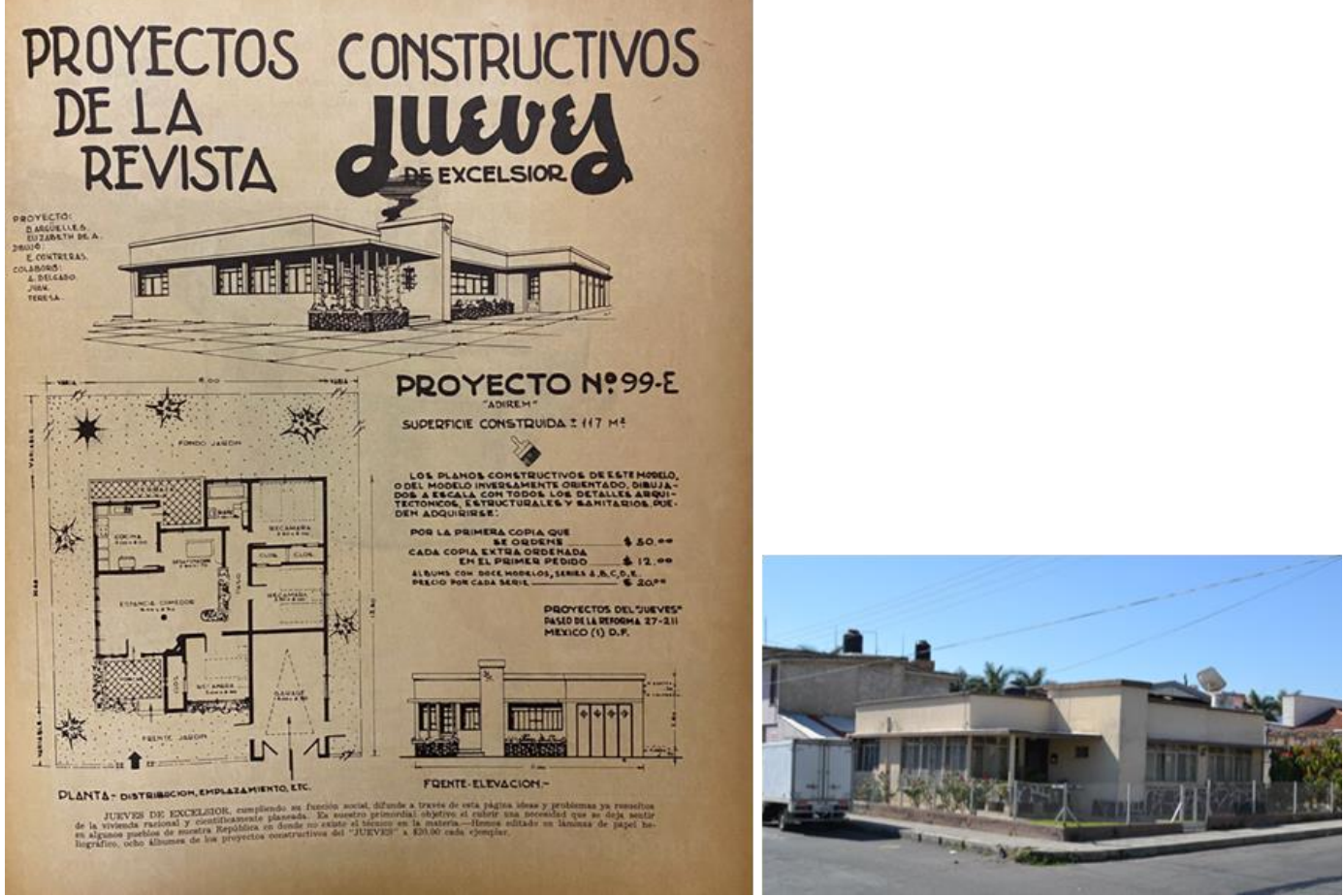

Fuente del proyecto: Revista Jueves de Excélsior no 1778 del 16 de agosto de 1956; Hemeroteca Histórica de la Biblioteca Pública del estado de Jalisco: Juan José Arreola. Fuente de la imagen: Fotografía del autor.

ACE, 16 (4.7) CC BY-ND 3.0 ES | UPC Barcelona, España | Sobre el modernismo provinciano en México. La Casa de 
En ambos modos se tendrían situaciones destacables, aunque dos serían las más recurrentes. Una corresponde a los materiales y el sistema constructivo, y la otra tendría que ver con el ajuste y la idealización del proyecto. La primera, y debido al propio contexto de la ciudad, estaría presente en los dos modos; la ausencia del profesional del diseño y de materias primas propias del modernismo, serían sustituidos por mano de obra artesanal y materiales de construcción tradicionales que, en el proceso de conciliación, favoreció el surgimiento de regionalismos y manieras reflejadas principalmente en ornamentos, techumbres y cornisas.

La segunda situación sería la que revelaría resultados heterogéneos. Los diseños de La Casa de la Semana muestran un estadio idílico; continuamente se desplantan en esquina o con un jardín perimetral, ello, además de resultar estéticamente atractivas, daban ventilación e iluminación natural, algo que, en la realidad, y por las medidas y geometría de las parcelaciones, sobre todo en el primer modo, debía ajustarse con recortes de espacios o modificaciones parciales del proyecto; no así las de calca que, contrario a las de adaptación, era el terreno el que se ajustaba al proyecto, tal como lo sucedido en la casa "La Gloria" que hubo de colocar artificialmente terraplenes para parecerse al ideal.

\section{A manera de cierre}

Si lo artístico es para el diseño, y lo estético para su lectura, en la arquitectura ambas situaciones están presentes, pero ha sido en la modernidad, y su lenguaje científico, lo que ha unido a los tres en su propuesta de lo moderno. Ahí, el conocimiento es universal, así que las decisiones lo son también. La certidumbre se aloja en una sociedad que busca un-porvenir que ha llegado bajo el sinónimo de progreso. Nadie quiere ser no-moderno. Esa racionalización viene aparejada con la ciencia, la tecnología y sus nuevos artefactos, por lo que la casa -su casa- debía ser para darle cabida y reflejo, y Jueves de Excélsior está al alcance y da ese alcance, es un inmejorable mediador entre lo universal y lo local, es un estándar que adquiere y traduce a otro estándar cerrando el ciclo de miradas.

Así que, ¿cómo debemos entender la casa del modernismo de la provincia mexicana? Debe seguirse a un pretendido burgués no próspero, el de la clase emergente que, por no parecer de abajo, aspira a la de arriba, y en esa búsqueda en medio se queda. Aquél que no podía vivir ni en la histórica traza virreinal, ni en el fraccionamiento periférico porque ambos han elevado su precio por la súbita demanda de suelo; el de las parcelaciones de la posrevolución y de la posguerra, siempre que tales promociones urbanas no se denominen colonias; aquél que no alcanzaba a cubrir a un profesional del diseño, pero tampoco se resignaba -ni podía- prescindir de un proyecto que, en la cotidianidad, el dibujo de un plano podía suplirlo.

Pero no cualquier plano, no el del dibujante que copia para las clases bajas como parte del mercado de los nuevos oficios. La Casa de la Semana es la alternativa doble: incluye los adelantos del modernismo, y hace a su usuario parte de una sociedad universal; con ello, y sin proponérselo, a la vez que genera identidad, produce una conciencia de clase, un Modo de Vida al afectar los gustos de esa colectividad y, por extensión, de los Estilos -sus estilos- de Vida que, al final, redime y remite a asuntos de adaptabilidad cuando selecciona la mejor opción para su vida familiar y su vida individual.

Esa imitación no es inocua, produce un ideal arquitectónico. La casa de los de en medio es una aspiración de una domesticidad que vive entre el pasado y el futuro, en un desenfado que combina lo nuevo con lo viejo, por lo que el decorativismo simbólico convive con un funcionalismo genérico, y que si bien da la espalda a la habitación en suite corrida, a la cocina con hornilla de leña y al baño exterior - a la usanza de las casas de las colonias populares- no hay reparo en introducir la chimenea; después de todo, ese elemento del pasado de un mundo idílico de otras latitudes, la revista nacional

ACE, 16 (47) CC BY-ND 3.0 ES | UPC Barcelona, España | Sobre el modernismo provinciano en México. La Casa de 15 la Semana en Jueves de Excélsior. DOI: http://dx.doi.org/10.5821/ace.16.47.10371 
y el cientificismo del proyecto lo respalda, así que da igual que sea simulada o funcional, es un símbolo de estatus social: lo racional es también emocional.

Es el tiempo de la clase media, la casa ya no es para trabajar. Los espacios para el ocio y lo privado complementan su domesticidad y su discurso, se hacen parte de la casa, se integran, pero siempre separadas. Así, la cocina es un elemento distintivo, ahí se aprecia la barra de línea de montaje, ahí se alojan los adelantos técnicos y tecnológicos, los artilugios de una modernidad divertida, de ilusión de progreso: los electrodomésticos; pero no es lo único, la habitación se aísla del resto, se hace privada, separa actividades y se separa de lo público; también el aseo es una actividad que requiere su espacio íntimo, el higienismo se personifica en el solárium y en el baño, este último, al igual que el porche, es de tipo americano, como lo es la cochera o el garaje que también aparece como un espacio novedoso que sustituye, aunque no siempre es así, a las caballerizas prerrevolucionarias.

La Casa de la Semana es un modelo, es un tipo ideal, es historiografía ignorada de la arquitectura nacional. Casos de estudio empíricos para poner a prueba una quimera: el método científico aplicado al diseño; el viejo sueño de democratizar la arquitectura estandarizándola; la respuesta inequívoca y científica, resolución universalizada a un problema individualizado, es decir, a un cliente único e hipotético y por ello inexistente. Es un modernismo impreso que persuade eficazmente a una clase media que, en su pretensión de clase, desea mostrarse ilustrada y, desde ahí, construye sus casas y construye su imaginario. Así, este peculiar modernismo de las casas provincianas se convertiría en conocimiento idealizado, de certidumbre no comprobable pero sí satisfactoria, y solo por ello -o a pesar de ello-, como toda teoría cientificista o hipótesis imposible, en un mito: el mito del modernismo.

Conflicto de intereses: El autor declara que no hay conflicto de intereses.

\section{Bibliografía}

Anda de, E. (2007). El proyecto de Juan O 'Gorman para el concurso de "vivienda obrera" de 1932. En N. Santiago. (Ed.), Arquitectura moderna en México (pp.155-171). México, México: Arquine.

Anda de, E. (2010). Cultura arquitectónica de la modernidad mexicana. Antología de textos 1922-1963. México; México: UNAM.

Ayala, E. (2006). Casas del siglo XX. México; México: CONACULTA.

Bachelard, G. (2000). La formación del espiritu cientifico. Contribución a un psicoanálisis del conocimiento objetivo. México, México: Siglo XXI.

Ball, J. (1961). The Urban Geography of Tepic, Nayarit, México: a study of changing functions (PhD diss). Recuperado de https://d.lib.msu.edu/etd/34571/datastream/OBJ/view

Berman, M. (1988). Todo lo sólido se desvanece en el aire. La experiencia de la modernidad. Tercera Edición. Buenos Aires, Argentina: Siglo XXI.

Bloch, M. (2000). Introducción a la historia. México: México: FCE

Bochenski, I.M. (1997). La Filosofía Actual. México, México: FCE.

Bunge, M. (1980). Epistemología. Curso de actualización. México, México: Siglo XXI.

ACE, 16 (47) CC BY-ND 3.0 ES | UPC Barcelona, España | Sobre el modernismo provinciano en México. La Casa de

la Semana en Jueves de Excélsior. DOI: http://dx.doi.org/10.5821/ace.16.47.10371 
Canales, F. y Hernández, A. (2017). $100 x 100$ Arquitectos del siglo XX en México. México, México: Arquine.

Canales, F. (2013). La modernidad arquitectónica en México; una mirada a través del arte y los medios impresos (Tesis doctoral). Recuperada de http://oa.upm.es/21350/1/ANA FERNANDA CANALES GONZALEZ.pdf

Canales, F. (2021). Mi casa, tu ciudad. Privacidad en un mundo compartido. Barcelona, España: Puente Carritt, E. (1992). Introducción a la Estética. México, México: FCE.

Ching, F.; Jarzombek, M. y Prakash V. (2011). Una historia universal de la arquitectura. Un análisis cronológico comparado a través de las culturas. Vol 2. Del siglo XV a nuestros días. Barcelona, España: GG.

Colquhoun, A. (2005). La arquitectura moderna. Una historia desapasionada. Barcelona, España: GG.

Cox R. y Buchli V. (2017). Series preface: ¿why home? En V. Buchli y R. Cox (Eds), Making home. Ethnography and design (pp. xii-xiii). London, UK: Bloomsbury.

Croce, B. (1982). Estética como ciencia de la expresión y lingüística general. Culiacán, México: UAS.

Cueva, M. (2010). Clase media, poder y mito en el México posrevolucionario: una exploración. Estudios políticos, (20), 105-129. Recuperado de http://www.scielo.org.mx/scielo.php?script=sci arttext\&pid=S0185-16162010000200006

Dacal, J. (2003). Estética General. México, México: Porrúa.

Díaz, I. (1991). Ignacio Díaz Morales habla de Luis Barragán: conversación con Fernando González Gortazar. Guadalajara, México: U. de G.

Dilthey, W. (1994). El Mundo Histórico. México, México: FCE.

Dorotinsky, D. (2014). Después de las utopías, la nostalgia. El siglo XIX y su recepción en el siglo XX. Anales del Instituto de Investigaciones Estéticas. XXXVI (105), 9-38. Recuperado de http://www.scielo.org.mx/scielo.php?pid=S0185-12762014000200002\&script=sci abstract\&tlng=es

Echeverría, B. (2013). Qué es la modernidad. México, México: UNAM.

Flores, C. (2015). Ciudad, arquitectura y sociedad. El movimiento moderno de Tepic. Parte // Urbanística y Urbanización. Tepic, México: UAN-UAS.

Flores, C. (2019). Sobre el modernismo en la arquitectura habitacional en México. Una reflexión epistémica. Revista de Direito da Cidade. 11(1), 277-309. DOI: https://doi.org/10.12957/rdc.2019.35675

García, R. (2006). Epistemología y teoría del conocimiento. Salud Colectiva, 2(2), 113-122. Recuperado de https://www.redalyc.org/pdf/731/73120202.pdf

Geddes, P. (2009). Ciudades en Evolución. Oviedo, España: KRK.

Gili, M. (Ed). (1999). La última casa. Barcelona, España: GG.

Goeritz, M. (1960). ¿Arquitectura Emocional? Revista Arquitectura: ENA, (8), 17-22. Recuperado de https://icaa.mfah.org/s/en/item/741755\#?c=\&m=\&s=\&cv=\&xywh=-1673\%2C0\%2C5895\%2C3299

Gómez, A. (2016). Características del Art Déco en Jalisco. En González A. (Coord.), Art Déco Tapatio (pp. 30-40). Guadalajara, México: Arquitónica.

ACE, 16 (47) CC BY-ND 3.0 ES | UPC Barcelona, España | Sobre el modernismo provinciano en México. La Casa de 17 la Semana en.Jueves de Excélsior. DOI: http://dx.doi.org/10.5821/ace.16.47.10371 
González, R. (2015). Comunidad virtual de amateurs con estándares profesionales (proams) en la replicación de productos editoriales comerciales. Paakat: Revista de Tecnología y Sociedad, 5 (9), s. p. Recuperado de https://www.redalyc.org/articulo.oa?id=499051500005

Gutiérrez R. y Méndez, P. (2009). Las revistas de arquitectura en Latinoamérica: perfiles de su historia y apuntes para su futuro. Bitácora arquitectura, (19), 12-17. Recuperado de http://www.revistas.unam.mx/index.php/bitacora/article/view/25102

Habermas, J. (2016). Historia y crítica de la opinión Pública. La transformación estructural de la vida pública. Barcelona, España: GG.

Harvey, D. (1998). La condición de la modernidad. Investigación sobre los orígenes del cambio cultural. Buenos Aires, Argentina: Amorrortu.

Heredia, J. (2007). Juan O'Gorman, más allá del funcionalismo radical. Dos edificios sindicales reconsiderados. En N. Santiago. (Ed.), Arquitectura moderna en México (pp. 209-222). México, México: Arquine.

Heredia, J. (2020). El primer edificio moderno en México. Las casas gemelas de Paul Artaria y Hans Schmidt. México, México: Arquine.

Hernández, M. (2014). La casa en la arquitectura moderna. Respuestas a la cuestión de la vivienda. Barcelona, España: Reverté.

Heynen, H. (1999). Architecture and Modernity. A Critique. Massachusetts, USA: MIT.

Jiménez, V. (2007). Carlos Obregón Santacilia. En N. Santiago. (Ed.), Arquitectura moderna en México (125-141). México, México: Arquine.

Jones,W. (2014). Cómo leer casas. Una Guía sobre arquitectura doméstica. Madrid, España: Ediciones Akal.

Latour, B. (2007). Nunca fuimos modernos. Ensayo de antropología simétrica. Buenos Aires, Argentina: Siglo XXI.

Lazo, P. (2007). Hannes Meyer, tres fragmentos fortuitos del proyecto moderno en México: desagregación espontánea. En N. Santiago. (Ed.) Arquitectura moderna en México (pp. 95-112). México, México: Arquine.

Leidenberger, G. (2012). Tres revistas mexicanas de arquitectura. Portavoces de la modernidad, 19231950. Anales del Instituto de Investigaciones Estéticas, 34 (101), 109-138. DOI: https://doi.org/10.22201/iie.18703062e.2012.101.2430

Lévi-Strauss, C. (2012). Mito y significado. Madrid, España: Alianza.

Liernur, J. (2007). Prólogo. En E. de Anda. Vivienda Colectiva de la modernidad en México. Los multifamiliares durante el periodo residencial de Miguel Alemán (1946-1952) (pp. 11-23). México, México: UNAM.

López C. (2015). Las firmas de las primeras casas funcionalistas de Juan O'Gorman. Bitácora Arquitectura, (30), 132-137. DOI: http://dx.doi.org/10.22201/fa.14058901p.2015.30.56151

Mardones, J. y Ursua N. (2003). Filosofía de la Ciencias Humanas y Sociales. Segunda Edición. Barcelona, España: Antropos.

ACE, 16 (47) CC BY-ND 3.0 ES | UPC Barcelona, España | Sobre el modernismo provinciano en México. La Casa de 
Massey, D. (2012). Un sentido global de lugar. Barcelona, España: Icaria.

Mayne, T. (2019). Prólogo. En Mayne, T., \& Now Institute. 100 edificios del siglo XX (p 5). Barcelona, España: GG.

Mayne, T., \& Now Institute. (2019). 100 edificios del siglo XX. Barcelona: GG.

McDowell, L. (2000). Género, identidad y lugar. Un estudio de las geografías feministas. Madrid, España: Cátedra.

Meyer, H. (1941). El regionalismo en la edificación de la vivienda suiza. Arquitectura. Selección de arquitectura, urbanismo y decoración. (7), 30-41. Recuperado de https://fa.unam.mx/editorial/wordpress/wp-content/Files/raices/RD06/REVISTAS/7.pdf

Meyer, J. (1997). Breve historia de Nayarit. México, México: FCE.

Montaner, J. y Muxí, Z. (2013). Arquitectura y política. Barcelona, España: GG.

Montaner, J. (2011). La modernidad superada. Ensayos sobre arquitectura contemporánea. Barcelona, España: GG.

Montañez, G. (2009). Encuentros, desencuentros y reencuentros recientes de la geografía, las ciencias sociales y las humanidades. En Chávez, M; González O. y Ventura, M. (Eds.) Geografía humana y ciencias sociales. Una relación reexaminada (pp. 33-72). Zamora, México: El Colegio de Michoacán.

Munari, M. (2016). ¿Cómo nacen los objetos?: apuntes para una metodología proyectual. Barcelona, España: GG.

Noelle, L. (2009). La arquitectura mexicana en las publicaciones periódicas del siglo XX. Bitácora arquitectura, (19), s.p. Recuperado de http://www.revistas.unam.mx/index.php/bitacora/article/view/25105

Núñez, O. (2002). La consolidación moderna. En Peña, J. (Dir). Jalisco 100 años de arquitectura. Muestra de la arquitectura jalisciense del siglo XX (pp. 58-59). Guadalajara, México: Academia Nacional de Arquitectura, Capítulo Guadalajara.

Olivares, M. (2011). Juan O'Gorman: arquitecto funcionalista radical. México, México: INBA, CONACULTA.

Ong, W. (2016). Oralidad y escritura: tecnologías de la palabra. México, México: FCE.

Ortiz, J. (1998). Arte, publicidad y consumo en la prensa. Del porfirismo a la posrevolución. Historia Mexicana, $48 \quad$ (2), 411-435. Recuperado de https://historiamexicana.colmex.mx/index.php/RHM/article/view/2448/1969

Pallasmaa, J. (2018). Lo ojos de la piel. La arquitectura y los sentidos. Barcelona, México: GG.

Pérez, A. (1980). La génesis y superación del funcionalismo en arquitectura. México, México: Limusa.

Pöete, M. (2015). Introducción al urbanismo. Evolución de las ciudades. Lecciones de antigüedad. Oviedo, España: KRK.

Puente, M. (Ed). (2106). Conversaciones con Mies van der Rohe. Barcelona, España: GG.

Ramírez, A. (2017). Conversación con Luís Barragán. Guadalajara, México: Arquitónica.

ACE, 16 (47) CC BY-ND 3.0 ES | UPC Barcelona, España | Sobre el modernismo provinciano en México. La Casa de 
Ramírez, J. (1963). Comentarios sobre la arquitectura contemporánea de Jalisco. Cuadernos de Arquitectura. (11), xiii-xxviii. Recuperado de https://fa.unam.mx/editorial/wordpress/wpcontent/Files/raices/RD15/cuadernos/cuaderno 11.pdf

Ricalde, H. (2007). La repercusión del Eco de Mathias Goeritz. En N. Santiago. (Ed.), Arquitectura moderna en México (pp. 41-54). México, México: Arquine.

Rivera, R. (1966). Tendencias de la arquitectura mexicana. Arquitectura de Vanguardia en México. Cuadernos de arquitectura, (18), 3-4. Recuperado de https://fa.unam.mx/editorial/wordpress/wpcontent/Files/raices/RD15/cuadernos/cuaderno 18.pdf

Rossi, A. (2015). La arquitectura de la ciudad. Barcelona, España: GG.

Rossi, A. (2018). Posicionamientos. Barcelona, España: GG.

Rueda, C. (2016). Una mirada a la modernidad arquitectónica en Guadalajara. Guadalajara, México: Arquitónica.

Rybczynski, W. (2015). La Casa. Historia de una idea. Donostia, España: Nerea.

Segawa, H. (2010). La soledad de las antologías. En Anda, X. y Lizárraga, S. (Eds), Cultura arquitectónica de la modernidad mexicana. Antología de textos 1922.1963 (pp. 9-12). México, México: UNAM.

Sennet, R. (1997). Carne y Piedra. El cuerpo y la ciudad en la civilización occidental. Madrid, España: Alianza.

Vapñarski, C. (1963). Prólogo. En Merton, R.; West, P.; Jahoda, M y Selvin, H. (Eds), Sociología de la vivienda (pp. 9-26). Buenos Aires, Argentina: HS.

Vargas, R. (Coord). (2009). Historia de la arquitectura y el urbanismo mexicanos. Volumen IV. El siglo XX. Tomo I. Arquitectura de la Revolución y revolución de la arquitectura. México, México: FCE.

Vargas, R. y Arias V. (Coord). (2010). Idearios de los arquitectos mexicanos. Tomo I, II y III. México, México: INBA-Conaculta.

Venturi, R. (2018). Complejidad y contradicción en la arquitectura. Barcelona, España: GG.

Wallerstein, I. (2007). Impensar las ciencias sociales. Limites de los paradigmas decimonónicos. Quinta Edición. México, México: Siglo XXI.

Waisman, M. (1990). El interior de la historia. Historiografía arquitectónica para uso de latinoamericanos. Bogotá, Colombia: Escala. 